\title{
Undergraduates Students' Learning Experience on the Impact of Online Learning during Pandemic
}

\author{
Muhd Khaizer Omar*, Monzurul Hassan, Nurazidawati Mohamad Arsad, Normala Ismail, \\ Rahimah Jamaluddin, Rosnani Jusoh
}

Faculty of Educational Studies, Universiti Putra Malaysia, 43400 Serdang Selangor, Selangor, Malaysia

Email: ^khaizer@upm.edu.my, hassanmonzurul.upm@gmail.com, azidarsad@yahoo.com.my, malaismail@upm.edu.my, imah_upm@upm.edu.my, rj@upm.edu.my

How to cite this paper: Omar, M. K., Hassan, M., Arsad, N. M., Ismail, N., Jamaluddin, R., \& Jusoh, R. (2021). Undergraduates Students' Learning Experience on the Impact of Online Learning during Pandemic. Open Journal of Social Sciences, 9, 167-184. https://doi.org/10.4236/jss.2021.99012

Received: August 15, 2021

Accepted: September 4, 2021

Published: September 7, 2021

Copyright $\odot 2021$ by author(s) and Scientific Research Publishing Inc. This work is licensed under the Creative Commons Attribution International License (CC BY 4.0).

http://creativecommons.org/licenses/by/4.0/

\begin{abstract}
The Coronavirus pandemic has shifted the norms and standard practices in the education setting and significantly impacted higher education. This unprecedented situation has created uncertainties in students' learning and the instructional process in general. Hence, the aim of this study was to explore the learning experience of students during this Covid-19 pandemic. A total of 68 informants among undergraduate and postgraduate students from Universiti Putra Malaysia (UPM) participated in this case study. They were asked to share their learning experiences via open-ended questions that were distributed via an online data collection platform called "JotForm". The narrative responses were analysed using thematic analysis. Five themes emerged from the narrative analysis: 1) Institutional support, 2) emotional engagement, 3) cognitive engagement, 4) behavioural engagement, and 5) students' satisfaction. The results: 1) amplified the urgent call for a reliable internet connection to facilitate the online instruction process, 2) proved the readiness of lecturers to adopt online teaching, 3) showed the need to create a conducive online learning environment, and 4) indicated the need to foster learning satisfaction. The deadly pandemic has continued to spread unabated all over the world, but education at all levels must continue. Therefore, appropriate measures must be put in place to facilitate the instruction process for the whole community of learners.
\end{abstract}

\section{Keywords}

Engagement, Institutional Support, Online Learning, Pandemic, Satisfaction

\section{Introduction}

The Covid-19 outbreak, which was declared a global pandemic by the World 
Health Organization on March 11, 2020, after China alerted WHO of its existence on December 31. 2019, has impacted over 80\% of the worlds' student population due to the closure of schools and universities worldwide. Due to the rapid rise of Covid-19 cases in literally every country, closing education institutions seems to be the right move in order to break the chain of this infectious disease. Since early 2020, a huge number of universities across the world had either postponed or cancelled all campus events, including workshops, conferences, and intra and inter university sports, and other activities (Sahu, 2020). After staying away from attending schools and universities for about a year now, the situation is gradually turning positive for students as many countries have decided to reopen all educational institutions this year, with detailed precautions put in place to protect students. During the "forced" break from normal classes since early last year, both students and educators had to make do with learning and teaching online. This digital approach is expected to continue even when students return to their faculties as usual.

Online learning is the best approach for educators and learners to ensure there is continuity in education during the current ordeal (Morgan, 2020). But the reactions to online education are mixed, where some are for it and others against. Mukhtar et al. (2020) are all for its flexibility while Bączek et al. (2021) praise its ease of access to educational materials and the privilege for students to pick the time and place to study. Another key advantage of online learning is the promotion of student-centred learning, where interactive pedagogy was created to keep students very much engaged in their studies. In a way, this method of teaching shifts the main responsibility of learning to the students (Dhawan, 2020; Rayens \& Ellis, 2018).

But online learning also has its downsides, including difficulties in teaching, limited attention span, and lack of attentiveness among students (Mukhtar et al., 2020). In addition, academic integrity is also an issue. Muhammad et al. (2020) cautioned that students could easily copy content from the internet to prepare their assignments or tasks without giving proper citations or references. Bączek et al. (2021) also raised the challenge of poor interaction between students and educators.

To develop an effective online learning environment, Dong et al. (2009) and Uden et al. (2007) suggested the setting up of an e-learning ecosystem, while Martins et al. (2020) and Ouf et al. (2017) proposed a smart learning version of it. These proposed online learning ecosystems basically need to be supported with the appropriate learning guidelines. Morgan (2020) suggested adopting the guidelines recommended by the International Society for Technology in Education (ISTE), which contained best practices for the implementation of online learning for both learners and educators. The guidelines include: 1) ensuring equity, 2) communicating expectations clearly, 3) providing student-centred learning, 4) using free high-quality resources, 5) responding to the emotional toll, and 6) using ISTE standard for students and educators. However, to increase the effective use of this online learning approach during the current pandemic, it is necessary 
to gather the views and perceptions of the students as they have differing opinions of this learning method. Meanwhile, several studies on higher education have been conducted for students in the medical fields (Bączek et al., 2021; Mukhtar et al., 2020; Rajab et al., 2020), but there is a lack of such a study in Malaysia, especially one focusing on undergraduates in the social science field and using the qualitative method. Therefore, this study aimed to explore students' perspective on their learning experiences and learning struggles during the Covid-19 outbreak.

\section{Literature Review}

The Covid-19 outbreak has upended the education sector globally, leaving the relevant authorities to scratch their heads as to how best to get the learning process back on track during these trying times. School closures are happening everywhere; hence, students encounter psychosocial and psychological issues that hampered their motivation to learn (Cao et al., 2020). There is no doubt that a possible educational disruption and confusion about the future of students are two of the unavoidable impacts of the pandemic. Even worse, a more profound emotional experience may await many students (Franchi, 2020; Sundarasen et al., 2020). The hesitance of educational stakeholders is obvious and the unprecedented disruption of common instruction practices is evident; hence, effort to bring education back onto the right track is necessary.

The unexpected transformation from face-to-face learning to online learning had created a lot of anxieties and frustrations among educational stakeholders, especially those who have problems accessing technology or those who simply refuse to get on the transformation bandwagon. Additionally, Azoulay (2020) highlighted that finding the solutions for hi-tech, low-tech, and no-tech facilities to ensure the continuity of learning in rural, uncharted, and under-developed nations essentially required an intensive strategy. The significant strategy in education is the impact of the pandemic on student learning. The learning has become an anomaly, where educators have an inclination for online learning but at the same time students are struggling and concerned with how vulnerable their education progress has become. It has become a challenge to learn in disruptions as the case of a re-spreading, while the curable measures are still unknown.

Due to the pandemic, educators and students seek any conducive environment they can find to accomplish "learning". They believe that online learning is the way to achieve meaningful and positive learning experiences. Thus, it is essential to educate the learners' community in the most limited capacity and in an affordable manner. The academic scenario in this respect goes beyond the teaching and learning norms. A forward-thinking, analytical strategy and realistic approaches are necessary to face the crisis (Rose, 2020). Taking this scenario in a prudent manner, the presence of a flipped classroom to provide individualised instruction "anytime, anywhere" through asynchronous learning should be carefully implemented. In recent years, many university faculties have transited from a tangible classroom to isolated home-based localities to carry out instructions. 
It is rather difficult to alleviate the concerns of students and educators regarding how effective this learning process is and how good the accessibility to online learning content is.

Higher education institutions around the world are turning to online learning or distance learning programs. The benefit is that it will allow students to learn at their convenience, as there is no need to attend training centres and universities (Knebel, 2001). This huge shift to online education does not involve faceto-face contact between teachers and students, along with their classmates, to avoid and monitor the spread of the lethal virus. While this online delivery can pose obstacles to teachers because they need to learn online skills in the preparation, implementation, and performance evaluation of their students, providing teachers with appropriate training for the courses will enable them to effectively execute the courses through electronic delivery (Yusuf, 2020). Various apps with creative tools for teachers are available to facilitate learning for students with diverse educational needs. Technology tools, program design, teacher choices, responsive curriculum, and supportive stakeholders are critical and essential for the effective delivery of lessons in the online environment (Barr \& Miller, 2013). Hence, this serves as an incentive for higher education institutions to increase the preparations of online learning teachers. A good teacher preparation in teacher education programs may enhance students' performance, which promotes goals that are consistent with the learning objectives of institutions of higher learning (Ludeman et al., 2009).

Moving on with the application of online learning, Bao (2020) listed five highimpact principles for online education: 1) high relevance between online instructional design and student learning, 2) effective delivery for online instructional information, 3) adequate support provided by faculty and teaching assistants to students, 4) high-quality participation to improve the breadth and depth of student's learning, and 5) contingency plan to deal with unexpected incidents of online education platforms. These principles are relevant to invigorate learners' and educators' motivation towards education. In addition, educational stakeholders among parents, teachers, and students should be prudent in their roles during this unprecedented crisis because if the situated learning process is not optimistically supported, this situation can hamper the strategic planning for education processes.

In this context, this study utilises the model of online learners' engagement and satisfaction by Kucuk and Richardson (2019) to identify learners' experience in learning during the Covid-19 upheavals. Students' engagement involved the use of resourceful educational platforms, such as Moodle and learning management systems, to assist splendid progress in the students' online learning process (Jalil et al., 2019; Lim et al., 2020a; Lim et al., 2020b). Following several attempts to communicate with students, teachers are being efficiently trained until they master the methods of distribution and accelerate learning through the use of information technology (IT) and the internet in a short period. Student satisfac- 
tion refers to their perceptions of educators' modifications of the pedagogical methods to accommodate their immediate needs (Abd Rahim et al., 2017; Ghadirin et al., 2018). This online learning environment, also called e-Learning, contributes to productive learning, exploratory learning, experiential learning, expanded learning, extended learning, easy-to-use learning, and enhanced learning by optimising the student-centred learning approach (Goh \& Sandars, 2020). With a myriad of ways to teach students, the process of instruction now has extensive resources and enables to accommodate students' learning progress, even in the situation where the world is struggling with a health crisis.

\section{Methodology}

\section{1) Research Design}

A qualitative method was utilised to collect data in order to achieve the purpose of this study. This research design allows a researcher to explore and understand the lived experiences of the study's participants (Merriam, 2009; Aydin \& Kaya, 2017). For this study, the data were obtained through a narrative reflection of experiences among university graduates.

2) Respondents and Context

A total of 68 informants among undergraduate $(n=58,85.3 \%)$ and postgraduate $(\mathrm{n}=10,14.7 \%)$ students of Universiti Putra Malaysia (UPM) participated in this study due to them being easily accessible and were taking the selected courses. The students were enrolled for one semester in three different courses, namely 1) foundation course Application of technology in product design (STE3610) $(\mathrm{n}=52,76.5 \%), 2)$ undergraduate course Career in organisation (TVE5004) $(\mathrm{n}=7,10.3 \%)$, and 3 ) postgraduate course Educational leadership (EAD5000) $(\mathrm{n}=9,13.2 \%)$. Table 1 shows the characteristics of the informants who participated in this study.

The students were required to sign up for the courses online since the Movement Control Order (MCO) prohibited students from being physically present at the university. Online learning via management system Putrablast, which is powered by Moodle, was launched by UPM for the benefit of its thousands of local and international students. Following the successful implementation of $\mathrm{Pu}$ trablast, students were able to access the courses online with ease and without having to attend face-to-face classes.

All course components, including the learning content and class meetings, were organised using either the asynchronous or synchronous methods via Zoom, Webex or Google Meet according to the different lecturers' preferences. The class sessions were recorded and uploaded to the Putrablast system, while links to these recorded sessions were distributed to the students using the WhatsApp application. For instance, group-based "Project on Outcome-Based Learning (PO-BL)" activity, assignments, and quizzes were designed based on the learner-centred approach and assessments were conducted using the online learning platform. These learning activities make up a total of $70 \%$ of formative assessment and 
Table 1. Characteristics profile of the informants.

\begin{tabular}{|c|c|c|c|}
\hline Characteristic & Profile & $n$ & Percentage \\
\hline \multirow{2}{*}{ Gender } & Male & 18 & 26.5 \\
\hline & Female & 50 & 73.5 \\
\hline \multirow{4}{*}{ Age } & $18-21$ & 47 & 69.1 \\
\hline & $22-25$ & 12 & 17.6 \\
\hline & $26-30$ & 7 & 10.3 \\
\hline & 30 and above & 2 & 2.9 \\
\hline \multirow{2}{*}{ Program } & Undergraduate & 58 & 85.3 \\
\hline & Post-graduate & 10 & 14.7 \\
\hline \multirow{3}{*}{ Course taken } & STE3610 & 52 & 76.5 \\
\hline & TVE5004 & 7 & 10.3 \\
\hline & EAD5000 & 9 & 13.2 \\
\hline \multirow{4}{*}{ Living place } & A village & 27 & 39.7 \\
\hline & A small city or town & 26 & 38.2 \\
\hline & A big city & 12 & 17.6 \\
\hline & Campus & 3 & 4.4 \\
\hline \multirow{2}{*}{ Highspeed internet plan (100 Mbps) } & Yes & 33 & 48.5 \\
\hline & No & 35 & 51.5 \\
\hline
\end{tabular}

$30 \%$ of summative assessment as the marks for the final examination.

As the forerunner of online education systems in Malaysia, UPM has produced hundreds of online courses to cater to students' learning needs. However, in contrast to the conventional teaching modes, the proportion of Massive Open Online Courses (MOOCs) is relatively limited, and the development of MOOCsbased content requires the time and effort of lecturers and university administration. Contrary to the limitations of MOOCs, UPM lecturers have rendered their best services via the Putrablast system to ensure minimal disruption in students' learning.

3) Data collection and analysis

JotForm, an online survey platform, was utilised to collect and compile the respondents' narrative reflections of their online learning process. Open-ended questions were formulated and validated by experts in online learning. The broad sense of the questions allowed the respondents to respond to the questions via narratives and storytelling, and the "openness" among the respondents was stimulated. Responses given by the respondents were bilingual, depending on the students' nationalities, and those responses in the Malay language were translated for reporting purposes. The narrative feedback from the respondents was then analysed thematically using constant comparative content analysis and colourcoded techniques using Microsoft Excel spreadsheets. The coding was classified into several categories based on previous studies. Intercoder agreement was at 
least $90 \%$ for each category. The themes that emerged from the study were then discussed to describe the subjects' responses to ensure that the authenticity and conformability of the narratives were guaranteed. This case study used narrative data derived from university students who could be contacted during the research period. The respondents were particularly attached to their personal lives amidst the Covid-19 outbreak, including, but not limited to, learning experience with online courses and perception of the influence of the online learning ecosystem on their thoughts and behaviours.

\section{Results}

Five themes emerged from the coding content analysis: 1) institutional support, 2) emotional engagement, 3) cognitive engagement, 4) behavioural engagement, and 5) teaching satisfaction.

1) Institutional supports

To safeguard access and continuity of education, the faculty switched from the conventional teaching and learning ecosystem to fully online teaching during the Covid-19 pandemic. The faculty probed the students' learning experiences in order to accommodate their needs. Based on the content analysis and coding under institutional support, the list of support mentioned by the informants is presented in Table 2.

The narrative content analysis result served as proof of the extent to which the faculty had gone to ensure the learning process proceeded as planned during the Movement Order Control (MCO) that was imposed nationwide For instance, Informant 22 shared his experience as follows: "The faculty had conducted a great deal of online learning and had provided support by providing learning records for students who were distracted by poor internet connection". Meanwhile, Informant 8 shared that "the faculty had taken various steps to ensure that the virtual classroom is as regular as the normal classroom".

Table 2. Institutional supports in online learning environment.

\begin{tabular}{ccc}
\hline Support & Total number mention & $\begin{array}{c}\text { Percentage informant mentioning } \\
(\mathbf{n}=\mathbf{6 8})\end{array}$ \\
\hline Putrablast & 8 & 12 \\
Online class & 20 & 29 \\
Online assignment & 3 & 4 \\
Online announcement & 2 & 1 \\
Google classroom & 1 & 4 \\
Google meet & 3 & 12 \\
Zoom & 8 & 16 \\
Recording online class & 11 & 3 \\
Whatapps & 2 & 3 \\
Total & 58 & 85 \\
\hline
\end{tabular}


The lecturers embraced the online learning environment immediately upon the imposition of the MCO. The university's administration abided by the government's instruction and had planned earlier in ensuring classes would continue as usual. The online learning initiative was executed by the lecturers, and Informant 9 reaffirmed that by saying that "they did such a good work because they tried hard to make sure all the lecturers were doing an online class". Noting that every student has limitations and difficulties to study online, Informant 54 said, "The lecturer took a good care of every student. In the case of no Internet, the teacher also left us a video so that we could study independently". Numerous strategies were implemented to make sure students learn at their convenience. This was indicated by Informant 45, who observed that "the faculty accommodated my learning needs. During COVID-19 the faculty used online learning materials. For example, Zoom and Google Meet and other online learning materials. We were also able to communicate through WhatsApp to ensure different tools being used to suit students' needs and the message was conveyed to each student effectively".

In support of earlier disclosure regarding the university's preparations for the online learning ecosystem, Informant 34 shared that the faculty had taken precautions early to address Covid-19-related issues, and one of them was by conducting online classes and minimising contact with each other. The power of Google Classroom was tapped to the full so that the students would always be alerted of the tasks given. The use of different online platforms enhanced the process of teaching and learning, where blended learning is regularly executed and has become a norm at the university. Hence, the online teaching is deemed convenient since students can get a stable internet connection anywhere around the campus.

2) Emotional engagement

When the Covid-19 nightmare will end is still a huge question mark. Hence, application of the new norm of learning and teaching seems to be longer than anticipated earlier. As classes remained virtual ones, students have developed various feelings towards certain courses. The narrative responses reflect the emotional engagement among students during online learning. Narrative content analysis showed three types of emotional engagement (See Table 3).

As shown in Table 3, Informant 67, for example, was struggling with a monotonous lesson that contributed to boredom and ultimately led to meaningless learning. The informant revealed that "sometimes I felt quite sleepy and there were times I felt lost because I did not focus". Similarly, Informant 53 reaffirmed the disclosure made by the previous informant by saying, "Honestly, attending online classes made me sleepier than attending an actual class. I did not fully understand what lecturers were saying because it was hard to focus".

The students' mental well-being becomes one of the crucial factors in an online learning environment. Some students have a tendency to get depressed and anxious when they are forced to participate in online learning, and they attend the online class simply to make sure that they fulfil the attendance requirement 
Table 3. Emotional engagement.

\begin{tabular}{|c|c|c|}
\hline Emotion & Total number mention & $\begin{array}{l}\text { Percentage informant mentioning } \\
\qquad(n=68)\end{array}$ \\
\hline \multicolumn{3}{|l|}{ Positive emotion } \\
\hline happy & 4 & 6 \\
\hline grateful & 1 & 1 \\
\hline feel safe & 1 & 1 \\
\hline excited & 3 & 4 \\
\hline comfortable & 1 & 1 \\
\hline fun & 1 & 1 \\
\hline good & 5 & 7 \\
\hline peaceful & 1 & 1 \\
\hline Negative emotion & & 0 \\
\hline sleepy & 2 & 3 \\
\hline uncomfortable & 1 & 1 \\
\hline stress & 8 & 12 \\
\hline disappointed & 2 & 3 \\
\hline mentally tired & 1 & 1 \\
\hline not interested & 1 & 1 \\
\hline sad & 2 & 3 \\
\hline \multicolumn{3}{|l|}{ Mixed feeling } \\
\hline happy and sad & 3 & 4 \\
\hline stress and fun & 1 & 1 \\
\hline sleepy and happy & 2 & 3 \\
\hline Total & 40 & 59 \\
\hline
\end{tabular}

for the course. Informant 46, for example, shared, "I felt so stressed and lost $m y$ concentration on my study".

However, at the same time, some students have a liking for online learning. Informant 67, for instance, praised her lecturer through her feelings in the narrative by declaring, "P $m$ happy because I have a dedicated lecturer to teach students and feel grateful to receive new input from the lecturer". Meanwhile, Informant 11 felt excited about the new learning environment and managed to handle his lessons more conveniently. He shared, "Excited. Because I have never experienced an online class. My study schedule at home is very systematic. I have more free time".

Some students have mixed emotions, as reflected in the narrative of Informant 21: " Mixed feelings were involved. Some days it stressed me out because of the internet line but some days I felt fun learning online classes as the lecturer made the learning fun". All in all, it is a fair argument that the students' emotions were unequivocal as Informant 26 elucidated, "At first, I am not very familiar and in- 
terested in online classes because I prefer face-to-face class. It makes me focus more and understand well. But with our situation right now, I can slowly adapt to this learning style and try my best to catch up and have a better understanding of every topic that we have learned".

3) Cognitive engagement

Cognitive engagement refers to students using their thinking besides engaging actively with their instructors and peers (See Table 4).

Based on the result from content narrative analysis, most students rarely or only sometimes interact with their instructors and peers. In addition, a number of students seemed to be struggling with the new learning experience and were unable to participate actively. For example, Informant 7 shared his frustration by saying, "I couldn't easily ask a question to my lecturer. I m not focused on online class". This reflection indicates that the teaching and learning do not sync for all students sometimes. Informant (57) said, "My learning process was disturbed because I did not understand what was being taught on the internet and did not have enough reading material to understand"., This described the limitation and hassle in gaining access to tangible resources, which disrupted the entire learning process.

Some students compared their before and during Covid-19 learning experiences with feelings of nostalgia. For instance, Informant 11 shared, "Anyhow, $I$ miss on-site class/learning as it will bring us closer to the lecturer and classmates, we can ask anything immediately and be able to get answers as soon as possible. Missing university environment." But she agreed that the deadly coronavirus could alter a person's life by saying, "But if you think about others and your life safety, it's better to be in a safe place like home".

The internet plays a critical role in bringing students, peers and teachers together. As described in the narrative responses, "internet connection" was the most repetitive term raised by the participating students. Difficulties in getting a good internet connection made it harder for the students to engage in learning effectively, so much so that they eventually became frustrated when it comes time to attend class online. Informant 33 portrayed her frustration this way: "Very2 stressful sir. Sometimes until I cry to get in the class but the internet connection doesn't want to support me at all". Since Informant 4 uttered that "my learning

Table 4. Cognitive engagement.

\begin{tabular}{ccc}
\hline Cognitive engagement & Total number mention & $\begin{array}{c}\text { Percentage informant } \\
\text { mentioning }(\mathrm{n}=68)\end{array}$ \\
\hline Interaction with instructor and peers & 4 & 6 \\
none & 22 & 32 \\
rarely & 14 & 21 \\
sometimes & 15 & 22 \\
often & 55 & 81 \\
Total & & \\
\hline
\end{tabular}


environment gets disrupted by poor internet connection", it indicated that the tool that connects people also play a significant role in motivating students in the online learning process. Hence, students used a Virtual Private Network (VPN) to get into a Moodle-based classroom platform. However, they also get disconnected, as mentioned by Informant 18: "I use a VPN to connect with people abroad. Sometimes VPN is not working so I can't get a message immediately". In another note, Informant 39 admitted that due to living in a remote place, he often struggled to gain internet access. He said it was "unfair for students like me. Because I live in a village and sometimes I don't have a good connection". Some of the informants are international students. They also face internet disruptions due to legal issues in their home country.

4) Behavioral engagement

On the basis that education must proceed even during difficult circumstances, like during a pandemic, lecturers prepared learning strategies and tasks for the students. The courses the students enrolled in emphasised on project-based tasks and required group work. The narrative analysis showed that the behavioural engagement among students was related to completing the assignments online, based on the strategies and tasks that were given (See Table 5).

The result from the narrative content analysis also unveiled feelings of frustration in uncompleted assignments in the context of learning satisfaction. Informant 4 voiced out her frustration with using an online platform by emphasising that she was "not satisfied because we are not able to complete the fieldwork and practical assignment". Full and partial interactions among members failed to produce solutions for their group project. It became a fall back to individual projects, where the group leader would be the one completing the project.

Table 5. Behavioral engagement.

\begin{tabular}{ccc}
\hline Behavioral engagement & Total number mention & $\begin{array}{c}\text { Percentage informant } \\
\text { mentioning }(\mathbf{n}=\mathbf{6 8})\end{array}$ \\
\hline Complete assignment & 12 & 18 \\
Manageable to complete & 14 & 21 \\
Sufficient assignment & & 12 \\
Uncompleted assignment & 8 & 6 \\
Overload assignment & 4 & 4 \\
Difficult to complete & 3 & 4 \\
Difficult to discuss in group work & 3 & 3 \\
Not understand & 2 & 4 \\
Lack of materials & 3 & 13 \\
Internet connection & & 7 \\
Attention & 9 & 93 \\
Cannot focus & 5 & 63 \\
Surrounding distraction & & \\
Total & &
\end{tabular}


Informant 3 and 61 reported similar experiences in learning via an online platform. The former said, " $P \mathrm{~m}$ mentally tired with online classes because I have to process a lot of information and juggling with assignments at the same time as the time given to finish everything isn't enough. It is difficult to follow the class schedule because the change from a normal of face-to-face classroom environment resulted in an online class arrangement based on the lecturer for the course" while the latter said, "It's a bit stressful because I don't want to miss class but at the same time there are two overlapping classes, it's hard for me to choose so I decided to open two and this is stressful but I try to hold and give my very best cause it s been a long time since classes have been sacrificed'.

Besides the involvement of students in completing given tasks, result from the narrative analysis also showed behavioural engagement relating to students' focus during online learning. Informant 51 explained, "Actually, I felt that I can't focus when attending the classes online. This is because I can easily get distracted when I am at home," while informant 13 added that "my emotions were stressed when I couldn't join the class and also stressed when I joined the class because I felt the class was not giving a positive impact for my study. It is because I do not focus well and I don't try to understand that in a short time". These suggest that all students have their own reasons for their perception that online learning do not suit their preferences.

The attention of students during online lessons was also distracted by their learning environment. Informant 26 was placed in the most difficult situation when she ended up being a helper in her sibling's house. She shared this experience as follows: "I was stuck at the house of my brother and sister who have a baby. The house was a common house, so it was a bit difficult for me to get the job done in a short time when I got disturbed by their kids. Also, managing my time at home and college is a bit different because in college I only need to focus as a student, but at home I need to focus as a student and on doing household chores for my sister and brother."

Some students proposed learning strategies to help them concentrate and complete the given tasks during online classes. Informant 33 and 23 suggested that lecturers use better pedagogical methods. Informant 33 suggested lecturers "make the online class more fun, so the student will enjoy and would not feel sleepy". Informant 23 made the following suggestion: "Make the learning and online class fun like conducting a few games or activities so it won't be boring". Informant 66 urged the faculty to "give some homework which students can do" to assist them in understanding the learning content. Since online learning has become less interesting because lecturers prioritise content rather than activities, Informant 39 said, "I need some exercise and supporting video (lecturers were teaching/presenting/a cartoon version/an example in real life, etc) to empower the lesson". Besides, the lecturer was able to upload the learning content, from reliable sources, in the form of activities that provide some additional learning content for students.

5) Students Satisfaction 
As the coronavirus continues to turn the world upside down, students and lecturers are uncertain about the future of the learning process. It is interesting to note the efforts being made by lecturers to ensure the pedagogical methods meet the goal of providing the best learning services to students. Table 6 shows students' satisfaction level regarding online learning.

Based on the content narrative analysis, only half of the participating students were satisfied with their learning experience during the Covid-19 outbreak. Informant 54 said, "I am satisfied enough with the virtual classroom because the lecturers do their best in their teaching and provide enough information." Informant 36 mentioned the important role played by the course lecturer to make class time worthwhile by affirming being "very satisfied. Because the teachers are very responsible, and I didn't waste the time this semester". This evidence shows that proactive lecturers will do everything to make sure that learning is possible amidst the current challenges and shortcomings.

However, some students are dissatisfied and frustrated. Informant 2 admitted that he was distracted by other matters during online learning and was "less satisfied because virtual learning has left me less focused and distracted". However, little information was given about the distracting factors that affected his learning. Informants 41 and 59 can be categorised as the most dissatisfied learners. Informant 41 said, " $P m$ not satisfied at all because $1 m$ the type of person who always ask my lecturer or teacher immediately if I don't understand something but this online class had limited me to ask my lecturer. Even I m asking about something I don't understand in WhatsApp's (example), I ll not understand even after that because I want specific explanation". Informant 59 felt "not so satisfied because usually, in normal classes, lecturers will draw or write more details to students on the whiteboard for them to understand more".

\section{Discussion}

To facilitate access and continuity of education while safeguarding the health of students during the Covid-19 pandemic, the university shelved the conventional teaching and learning ecosystem for online teaching. Due to this significant change, this study explored the impact of the Covid-19 outbreak on online learning from the perspective of UPM students. As aforementioned, five themes emerged from the analysis conducted, namely 1) institutional support, 2) emotional engagement, 3) cognitive engagement, 4) behavioural engagement, and 5) students' satisfaction.

Table 6. Students satisfaction.

\begin{tabular}{ccc}
\hline Students satisfaction & Total number mention & $\begin{array}{c}\text { Percentage informant } \\
\text { mentioning }(\mathbf{n}=\mathbf{6 8})\end{array}$ \\
\hline Satisfied & 36 & 53 \\
Less satisfied & 13 & 19 \\
Not satisfied & 18 & 26 \\
Total & 67 & 98 \\
\hline
\end{tabular}


The first theme touches on institutional support for students' learning. One initiative implemented by UPM was the offering of a virtual educational environment by using LMS Moodle to ensure its students can access the courses online, including learning materials, assessments, and tracking their progress. Kerimbayev et al. (2020) described LMS Moodle as a great strategic tool for planning, conducting, and managing learning activities. The results of the present study also demonstrate that the effort to use this open-source learning platform is a positive one as students could attend class as usual, even though it is a virtual classroom. To ensure that no lessons are missed, the university accommodates students with online recording and web or video conferencing that were organised using either the asynchronous or synchronous methods.

The findings also indicate that the effectiveness of this support system is reflected by the students' engagement in online learning. The results highlight the occurrence of three types of engagement during the online learning process: 1 ) emotional, 2) cognitive, and 3) behavioural. Georgakopoulos et al. (2020) assert that emotional engagement is difficult to measure, unlike behavioural engagement, which can be assessed through the interactions with learning activities. However, the results prove that emotional engagement among students can be determined by their positive or negative emotions, including attitude, enthusiasm, and interest in learning. Students developed positive emotions because the online courses were conducted asynchronously, giving them flexibility in scheduling and giving them more free time. In addition, this digital approach to learning makes it more fun and meaningful for students to engage in the planned activities. However, students also do develop negative emotions in online learning. Yu et al. (2020) asserted that the relationship between student interaction and learning persistence was mediated and moderated by anxiety and boredom. Students feel less sense of belonging and have difficulties in concentrating in this relatively new learning environment. The consistency of this negative emotional engagement will lead to poor academic performance.

Meanwhile, cognitive engagement focuses on how students use active learning and higher order thinking to master learning (Schindler et al., 2017). However, the findings show that the students seem to struggle to effectively engage in learning. They often have difficulties interacting with their instructors and peers. As a consequence, it was difficult for them to understand online learning content well. This one-way communication became a major obstacle for the instructors to provide meaningful learning to students. Instructors need to identify the best practices to communicate effectively in order to encourage students to participate in an online learning environment. Another challenge that also interfered with the students' cognitive engagement is internet connection. Unstable and poor internet connectivity make online learning difficult.

Behavioural engagement is also part of the students' experiences in online learning. This engagement refers to students' participation in completing assignments and their attention during online learning (Kucuk \& Richardson, 2019). Most of the students felt burdensome to complete the assignments given by their instruc- 
tors. In fact, group online projects represented the main challenge for them. Free riders, time consuming, limited verbal and unsynchronised communication are common factors hindering the effectiveness of completing group projects (Chang \& Kang, 2016). Regarding the students' attention in the virtual classroom, most of them were distracted by the home atmosphere as it was a non-private place to study. Apart from that, attention distractions often occur when students lack time management skills, which caused them to do household chores and class assignments simultaneously. Some students suggested new learning strategies to help them develop deeper engagement and achieve online learning satisfaction.

Quality teaching is believed to directly influence students' satisfaction. Masserini et al. (2019) believed teaching quality dimensions to be the main determinants of students' satisfaction. The findings of this study indicate that students were satisfied when the teachers deliver good teaching quality. However, some students also expressed their dissatisfaction with their lecturers' teaching style in online learning classrooms. Hence, to improve the pedagogical strategy, lecturers should strive to utilise numerous online learning platforms, such as Zoom, Webex, and Google Meet. In most cases, lecturers are still adapting and trying to understand the whole functionality of the various online learning platforms. In some online classes, lecturers focus more on content delivery rather than developing interactive content in the form of student-centred learning and game-based learning. Hence, their students might feel dissatisfied because they did not get the same treatment they received in conventional classrooms. Overall, there are still barriers to implementing online learning at home because not all students have good internet access. Technological facilities have become the major barrier to online learning. As a matter of fact, not all students can afford the required technological tools.

\section{Study Limitation}

The current study was limited to students of UPM, Malaysia. Hence, the findings of this study cannot be generalised to all institutions of higher learning in the country. The emotions and perceptions of the faculty regarding the usage of technology and knowledge are different for different users. We identified numerous technical issues when it comes to data consumption and usage. Future studies can address this research gap and focus on other modes to collect empirical data that can be analysed for better results. In addition, future studies can focus more on a hybrid system of education that is a mixture of both online and offline learning.

\section{Conclusion}

In view of this rapidly evolving global health crisis, the quality of learning is deemed more important than content delivery for both learners and educators; hence, a vast amount of trial and error in learning methods is necessary. For these strategies to be successful, institutions of higher learning should foster close cooperation among themselves, particularly in the form of regionalisation of edu- 
cational teleconferences and allowing access to nearby institutions to ensure all students have access to high-quality education during these trying times. This should include access to a stable internet connection. Private entities can assist by providing the necessary facilities and the government providing the necessary support to enable teaching and learning to take place effectively and without disruption. In the implementation of a distance-learning ecosystem, due emphasis must be given to support student learning in terms of emotion, cognition and behaviour. This means that all programs should contain appropriate measures to preserve these important elements.

\section{Conflicts of Interest}

The authors declare no conflicts of interest regarding the publication of this paper.

\section{References}

Abd Rahim, N., Abdul Halim, H., \& Mansor, N. S. (2017). E-Story and Writing Skill among Second Language Learners. Turkish Online Journal of Educational Technology, 16, 2732.

Aydin, H., \& Kaya, Y. (2017). The Educational Needs of and Barriers Faced by Syrian Refugee Students in Turkey: A Qualitative Case Study. Intercultural Education, 28, 456-473. https://doi.org/10.1080/14675986.2017.1336373

Azoulay, A. (2020). With One in Five Learners Kept out of School, UNESCO Mobilizes Education Ministers to Face the COVID-19 Crisis.

https://en.unesco.org/news/one-five-learners-kept-out-school-unesco-mobilizes-educa tion-ministers-face-covid-19-crisis

Bączek, M., Zagańczyk-Bączek, M., Szpringer, M., Jaroszyński, A., \& Wożakowska-Kapłon, B. (2021). Students' Perception of Online Learning during the COVID-19 Pandemic: A Survey Study of Polish Medical Students. Medicine, 100, e24821. https://doi.org/10.1097/MD.0000000000024821

Bao, W. (2020). COVID-19 and Online Teaching in Higher Education: A Case Study of Peking University. Human Behavior and Emerging Technologies, 2, 113-115. https://doi.org/10.1002/hbe2.191

Barr, B., \& Miller, S. (2013). Higher Education: The Online Teaching and Learning Experience. https://files.eric.ed.gov/fulltext/ED543912.pdf

Cao, W., Fang, Z., Hou, G., Han, M., Xu, X., Dong, J., \& Zheng, J. (2020). The Psychological Impact of the COVID-19 Epidemic on College Students in China. Psychiatry Research, 287, Article ID: 112934. https://doi.org/10.1016/j.psychres.2020.112934

Chang, B., \& Kang, H. (2016). Challenges Facing Group Work Online. Distance Education, 37, 73-88. https://doi.org/10.1080/01587919.2016.1154781

Dhawan, S. (2020). Online Learning: A Panacea in the Time of COVID-19 Crisis. Journal of Educational Technology Systems, 49, 5-22. https://doi.org/10.1177/0047239520934018

Dong, B., Zheng, Q., Yang, J., Li, H., \& Qiao, M. (2009). An e-Learning Ecosystem Based on Cloud Computing Infrastructure. 2009 Ninth IEEE International Conference on Advanced Learning Technologies, Riga, 15-17 July 2009, 125-127.

https://doi.org/10.1109/ICALT.2009.21 
Franchi, T. (2020). The Impact of the Covid-19 Pandemic on Current Anatomy Education and Future Careers: A Student's Perspective. Anatomical Sciences Education, 13, 312315. https://doi.org/10.1002/ase.1966

Georgakopoulos, I., Chalikias, M., Zakopoulos, V., \& Kossieri, E. (2020). Identifying Factors of Students' Failure in Blended Courses by Analyzing Students' Engagement Data. Education Sciences, 10, 242. https://doi.org/10.3390/educsci10090242

Ghadirian, H., Fauzi Mohd Ayub, A., \& Salehi, K. (2018). Students' Perceptions of Online Discussions, Participation and e-Moderation Behaviours in Peer-Moderated Asynchronous Online Discussions. Technology, Pedagogy and Education, 27, 85-100. https://doi.org/10.1080/1475939X.2017.1380695

Goh, P. S., \& Sandars, J. (2020). A Vision of the Use of Technology in Medical Education after the COVID-19 Pandemic. MedEdPublish, 9, 49.

https://doi.org/10.15694/mep.2020.000049.1

Jalil, H. A., Ma'rof, A. M., \& Omar, R. (2019). Attitude and Behavioral Intention to Develop and Use MOOCs among Academics. International Journal of Emerging Technologies in Learning, 14, 31-41. https://doi.org/10.3991/ijet.v14i24.12105

Kerimbayev, N., Nurym, N., Akramova, A., \& Abdykarimova, S. (2020). Virtual Educational Environment: Interactive Communication Using LMS Moodle. Education and Information Technologies, 25, 1965-1982. https://doi.org/10.1007/s10639-019-10067-5

Knebel, E. (2001). The Use and Effect of Distance Education in Healthcare: What Do We Know? The U.S. Agency for International Development (USAID) by the Quality Assurance Project. Operations Research Issue Paper, 2(2).

https://www.semanticscholar.org/paper/The-Use-and-Effect-of-Distance-Education-in -\%3A-WhatKnebel/cda9b3bd188a9541aed3e670ec8ba6a6f1516df7\#citing-papers

Kucuk, S., \& Richardson, J. C. (2019). A Structural Equation Model of Predictors of Online Learners' Engagement and Satisfaction. Online Learning, 23, 196-216. https://doi.org/10.24059/olj.v23i2.1455

Lim, C. L., Jalil, H. A., Ma'rof, A. M., \& Saad, W. Z. (2020a). Self-Regulated Learning as a Mediator in the Relationship between Peer Learning and Online Learning Satisfaction: A Study of a Private University in Malaysia. Malaysian Journal of Learning and Instruction, 17, 51-75. https://doi.org/10.32890/mjli2020.17.1.3

Lim, C. L., Jalil, H. A., Marof, A. M., \& Saad, W. Z. (2020b). Peer Learning, Self-Regulated Learning and Academic Achievement in Blended Learning Courses: A Structural Equation Modeling Approach. International Journal of Emerging Technologies in Learning, 15, 110-125. https://doi.org/10.3991/ijet.v15i03.12031

Ludeman, R., Osfield, K., Hidalgo, E. I., Oste, D., \& Wang, H. (2009). Student Affairs and Services in Higher Education: Global Foundations, Issues and Best Practices. United Nations Educational, Scientific and Cultural Organization, France. https://unesdoc.unesco.org/ark:/48223/pf0000183221

Martins, V. F., Tomczykv, Ł., Amato, C., Eliseo, M. A., Oyelere, S. S., Akyar, Ö. Y., Silveira, I. F. et al. (2020). A Smart Ecosystem for Learning and Inclusion: An Architectural Overview. In International Conference on Computational Science and Its Applications (pp. 601-616). Springer. https://doi.org/10.1007/978-3-030-58799-4 44

Masserini, L., Bini, M., \& Pratesi, M. (2019). Do Quality of Services and Institutional Image Impact Students' Satisfaction and Loyalty in Higher Education? Social Indicators Research, 146, 91-115. https://doi.org/10.1007/s11205-018-1927-y

Merriam, S. B. (2009). Qualitative Research: A Guide to Design and Implementation. Jossey-Bass.

Morgan, H. (2020) Best Practices for Implementing Remote Learning during a Pandemic. 
The Clearing House: A Journal of Educational Strategies, Issues and Ideas, 93, 135-141. https://doi.org/10.1080/00098655.2020.1751480

Muhammad, A., Shaikh, A., Naveed, Q. N., \& Qureshi, M. R. N. (2020). Factors Affecting Academic Integrity in E-Learning of Saudi Arabian Universities. An Investigation Using Delphi and AHP. IEEE Access, 8, 16259-16268.

https://doi.org/10.1109/ACCESS.2020.2967499

Mukhtar, K., Javed, K., Arooj, M., \& Sethi, A. (2020). Advantages, Limitations and Recommendations for Online Learning during COVID-19 Pandemic Era. Pakistan Journal of Medical Sciences, 36, S27. https://doi.org/10.12669/pjms.36.COVID19-S4.2785

Ouf, S., Abd Ellatif, M., Salama, S. E., \& Helmy, Y. (2017). A Proposed Paradigm for Smart Learning Environment Based on Semantic Web. Computers in Human Behavior, 72, 796781. https://doi.org/10.1016/j.chb.2016.08.030

Rajab, M. H., Gazal, A. M., \& Alkattan, K. (2020). Challenges to Online Medical Education during the COVID-19 Pandemic. Cureus, 12, e8966.

https://doi.org/10.7759/cureus.8966

Rayens, W., \& Ellis, A. (2018). Creating a Student-Centered Learning Environment Online. Journal of Statistics Education, 26, 92-102.

https://doi.org/10.1080/10691898.2018.1475205

Rose, S. (2020). Medical Student Education in the Time of COVID-19. JAMA, 323, 21312132. https://doi.org/10.1001/jama.2020.5227

Sahu, P. (2020). Closure of Universities due to Coronavirus Disease 2019 (COVID-19): Impact on Education and Mental Health of Students and Academic Staff. Cureus, 12, e7541. https://doi.org/10.7759/cureus.7541

Schindler, L. A., Burkholder, G. J., Morad, O. A., \& Marsh, C. (2017). Computer-Based Technology and Student Engagement: A Critical Review of the Literature. International Journal of Educational Technology in Higher Education, 14, 1-28.

https://doi.org/10.1186/s41239-017-0063-0

Sundarasen, S., Chinna, K., Kamaludin, K., Nurunnabi, M., Baloch, G. M., Khoshaim, H. B., Hossain, S. F. A., \& Sukayt, A. (2020). Psychological Impact of COVID-19 and Lockdown among University Students in Malaysia: Implications and Policy Recommendations. International Journal of Environmental Research and Public Health, 17, 6206. https://doi.org/10.3390/ijerph17176206

Uden, L., Wangsa, I. T., \& Damiani, E. (2007). The Future of E-Learning: E-Learning Ecosystem. 2007 Inaugural IEEE-IES Digital EcoSystems and Technologies Conference, Cairns, 21-23 February 2007, 113-117. https://doi.org/10.1109/DEST.2007.371955

Yu, J., Huang, C., Han, Z., He, T., \& Li, M. (2020). Investigating the Influence of Interaction on Learning Persistence in Online Settings: Moderation or Mediation of Academic Emotions? International Journal of Environmental Research and Public Health, 17, 2320. https://doi.org/10.3390/ijerph17072320

Yusuf, B. N. (2020). Are We Prepared Enough? A Case Study of Challenges in Online Learning in a Private Higher Learning Institution during the Covid-19 Outbreaks. Advances in Social Sciences Research Journal, 7, 205-212.

https://doi.org/10.14738/assri.75.8211 